\title{
Silane-coupled kenaf fiber filled thermoplastic elastomer based on recycled high density polyethylene/natural rubber blends
}

\author{
Cao Xuan Viet ${ }^{1}$, Hanafi Ismail' ${ }^{2}$ Abdulhakim Masa ${ }^{3}$ and Nabil Hayeemasae ${ }^{4 *}$ \\ ${ }^{1}$ Department of Polymer Materials, Faculty of Materials Technology, Ho Chi Minh City University of Technology \\ - HCMUT, Ho Chi Minh City, Vietnam \\ ${ }^{2}$ School of Materials and Mineral Resources Engineering, Universiti Sains Malaysia, Engineering Campus, \\ Nibong Tebal, Penang, Malaysia \\ ${ }^{3}$ Rubber Engineering and Technology Program, International College, Prince of Songkla University, Hat \\ Yai, Songkhla, Thailand \\ ${ }^{4}$ Department of Rubber Technology and Polymer Science, Faculty of Science and Technology, Prince of \\ Songkla University, Pattani Campus, Pattani, Thailand \\ *nabil.h@psu.ac.th
}

\begin{abstract}
A silane coupling agent, namely $\gamma$-aminopropyltriethoxysilane (APS), was used to modify kenaf powder (KP). It was then used as filler in a thermoplastic elastomer (TPE) based on Recycled High Density Polyethylene/Natural Rubber Blends (rHDPE/NR). The attachment of silane onto KP was verified by Fourier Transform Infrared Spectroscopy (FTIR), while the performance of the TPE was assessed in terms of mechanical and thermal properties. The results revealed that specific functional groups of APS were efficiently grafted onto the KP. Tensile strength was improved by the modification with silane and this also affected Young's modulus of the TPE. Also, improved thermal stability was confirmed by thermogravimetric analysis (TGA), as the degradation temperature increased upon inclusion of silane. These effects are attributed to improved compatibility of the KP and rHDPE/NR blend. Such compatibilizing effect was confirmed by Differential Scanning Calorimetry (DSC) that indicated significantly increased crystallinity after the modification with silane.
\end{abstract}

Keywords: recycled polyethylene, natural rubber, Kenaf powder, silane coupling agent.

How to cite: Viet, C. X., Ismail, H., Masa, A., \& Hayeemasae, N. (2021). Silane-coupled kenaf fiber filled thermoplastic elastomer based on recycled high density polyethylene/natural rubber blends. Polímeros: Ciência e Tecnologia, 31(2), e2021023. https://doi.org/10.1590/0104-1428.20210039

\section{Introduction}

The consumption of plastic materials in our daily life has been constantly increasing because of numerous consumer goods made of plastics. This consumption also creates problems and concerns regarding disposal and environmental impacts. This is because most plastics are not biodegradable, taking a long time to degrade in the nature, possibly even several centuries. With more and more plastic products, the landfill volume of plastics waste is a growing concern, interest in recycling post-consumer polymers has gained attention. The largest fraction of polymer wastes consists of polyolefins, such as polyethylene (PE) and polypropylene $(\mathrm{PP})^{[1,2]}$, and recycling is an alternative destination for these materials. Thermoplastic elastomers (TPE) are the materials of choice to widen the use of recycled plastics. TPE is a special class of viscoelastic materials that contain properties of thermoplastics and elastomers ${ }^{[3-5]}$.

The incorporation of various types of filler into a TPE is done either to improve the properties or to reduce the raw material costs. These cover many types of available fillers. Natural fiber has been one of efficient fillers to reinforce the polymer matrix. For examples, sisal fibers have been used to reinforce Polyurethane composite, it has shown an excellent thermal stability and mechanical properties ${ }^{[6]}$. Fibers from other plants were also used to enhance several composites' properties ${ }^{[7,8]}$. It can be clearly seen that the use of natural fiber in the thermoplastic composites is still considered a filler of choice in plastic composite. One of the interesting source of fiber is from Kenaf. Kenaf gains a lot of interest in the context of making composites as a filler in polymer matrix ${ }^{[9]}$. Kenaf stem composes of two distinct fiber types, in bark and core. On average the stem has $65 \%$ woody core and $35 \%$ of bark by weight ${ }^{[10]}$. The abundance of kenaf core combined with its easy processability are the main reason that make this material attractive characteristics to substitute commercial fillers which are potentially toxic. 
Although natural fillers can offer many advantages in composites, the polarity in nature of these fillers have considerably less compatible with non-polar polymer matrices, such as cis-polyisoprene (NR) and polyethylene (PE). Such disadvantage causes a bad dispersion of filler and gives poor interfacial adhesion between these two phases, leading to composites with rather poor durability and thermal stability ${ }^{[1]]}$. Hence, the surface treatment of natural fibers is the best solution to overcome this drawback. One of the most successful treatment is through the use of silane coupling agent, which has lately demonstrated the efficacy of various silane coupling agents in the modification of natural fibers ${ }^{[11,12]}$.

Silane interfacial coupling agents are widely applied on cellulosic fillers to form stable bonds with the polymer matrix ${ }^{[13]}$. Like other natural fibers, Kenaf powder (KP) also requires surface modification in order to increase its compatibility to the non-polar matrix. The use of silane coupling agent is believed to modify the surface functionality of the KP and subsequently enables KP to bond chemically to the rubber matrix. The aim of this research was to use a silane coupling agent in the composite that has KP filler in recycled high density polyethylene (rHDPE)/natural rubber (NR). Apart from that, dicumyl peroxide (DCP) was also introduced, DCP is considered to be suitable crosslinker for both $\mathrm{PE}$ and $\mathrm{NR}^{[14]}$. It was expected to promote cocrosslinking between rHDPE and NR. To date, no prior report has been published on the potential of this approach. This work focused on the mechanical properties and the morphology of the composites as well as their thermal stability. The results obtained from this present study will improve scientific understanding of how a silane coupling agent and DCP could influence the properties of KP filled rHDPE/NR blends.

\section{Materials and Methods}

\subsection{Materials}

Recycled high density polyethylene (rHDPE) was obtained from Zarm Scientific and Supplies Sdn Bhd, Penang, Malaysia. The melt flow index of rHDPE was $0.237 \mathrm{~g}$ at $10 \mathrm{~min}$. The SMR 20 grade was supplied by Mardec Berhad, Selangor, Malaysia., $\gamma$-aminopropyltriethoxysilane (APS) and dicumyl peroxide (DCP) were supplied by SigmaAldrich (M) Sdn Bhd, Selangor, Malaysia. Kenaf powder was obtained from core part and it was ground using a table-type pulverizing machine until getting the size ranging from 32 to $150 \mu \mathrm{m}$ was received.

\subsection{Preparation of silane-treated KP}

The treatment of KP was done by immersing KP in $\mathrm{NaOH}$ solution $(5 \% \mathrm{w} / \mathrm{v})$ for $2 \mathrm{~h}$ at room temperature. Then KP was washed with distilled water containing a few drops of acetic acid washed again with distilled water and dried. Next, silane treatment was carried out in a mixture of water/ethanol $(30 / 70 \mathrm{v} / \mathrm{v})$ for the pretreated KP. The $\mathrm{pH}$ of the solution was adjusted to 4 with acetic acid and stirred for $1 \mathrm{~h}$. Then, $10 \mathrm{~g}$ of KP was soaked in the solution and continuously stirred for $3 \mathrm{~h}$. The silane-treated KP was filtered and dried in a vacuum oven at $80^{\circ} \mathrm{C}$ for $24 \mathrm{~h}$ prior to compounding

\subsection{Preparation of the blends}

Table 1 lists the formulations used for preparing the TPE based on KP filled rHDPE/NR composites. There are three alternative types of formulations, namely untreated KP filled rHDPE/NR composites (KP), silane-treated KP filled rHDPE/ NR composites (KP-APS) and silane-treated KPrHDPE/NR composites in the presence of DCP (KP-APS-DCP). These three types of composites were compared in order to select ingredients for achieving the best composite. The mixing was done in an internal mixer (Haake Rheomix Polydrive R600/610 mixer) with a rotor speed of $50 \mathrm{rpm}$ at $165^{\circ} \mathrm{C}$. The rHDPE was firstly charged into the mixer and molten, followed by NR. After this, the steps in compounding depend on the method of preparation whereby the APS and/or APS/ DCP were added prior to introduce KP at the final step. The total mixing time was kept constant at 12 min for all composites. Samples collected from the internal mixer were compression molded in an electrically heated hydraulic press, model GT-7014-A30C. The molding involved preheating the samples for 8 min at $165^{\circ} \mathrm{C}$, followed by compressing at $100 \mathrm{~kg} / \mathrm{cm}^{2}$ for $3 \mathrm{~min}$ at similar temperature, and subsequently cooling down under pressure for another $2 \mathrm{~min}$.

\subsection{Mixing torque}

The torque was computationally recorded from Haake Rheomix Polydrive R 600/610 mixer at $10 \mathrm{sec}$ intervals while mixing. The development of torque over mixing time were assessed, while the torque at the end of processing was considered a stabilized torque.

\subsection{Tensile properties}

All the composites were tested under tension force at a cross-head speed of $50 \mathrm{~mm} / \mathrm{min}$ using an Instron 3366 machine according to ASTM D412. The specimens

Table 1. Formulations used to prepare KP filled rHDPE/NR composites.

\begin{tabular}{cccc}
\hline \multirow{2}{*}{ Material } & KP & Amount (php or phr) & KP-APS-DCP \\
\cline { 2 - 4 } & 70 & KP-APS & 70 \\
\hline rHPDE $^{\text {a }}$ & 30 & 70 & 30 \\
${\text { SMR } 20^{\mathrm{a}}}_{\text {KP }}^{\mathrm{a}}$ & $0,10,20,30 \& 40$ & 30 & $0,10,20,30 \& 40$ \\
APS & - & $0,10,20,30 \& 40$ & 1 \\
DCP & - & - & 0.05 \\
\hline
\end{tabular}

Remarks: a refers to parts per hundred of polymers (php) and b refers to parts per hundred of rubber (phr). 
were in dog-bone shape at $1 \mathrm{~mm}$ thickness. Prior to the test, the thickness were measured whereby the results were recorded in terms of tensile strength, Young's modulus and elongation at break.

\subsection{Scanning Electron Microscopy (SEM)}

The samples from tensile fractured surfaces were used to observe the morphological characteristics of the composites. It was captured using a Supra-35VP field emission scanning electron microscope (SEM). All the samples were sputter coated with gold/palladium using Bio-Rad Polaron Division device prior to scanning to prevent electrostatic charging during imaging.

\subsection{Thermogravimetric analysis (TGA)}

The thermal stability of the composites was determined using using Perkin Elmer TG-6 Analyzer. The sample was heated from $30^{\circ} \mathrm{C}$ to $600{ }^{\circ} \mathrm{C}$ at a heating rate of $10^{\circ} \mathrm{C} / \mathrm{min}$ in nitrogen atmosphere. The temperatures at various weight loss and char residue were recorded and further discussed to interpret the thermal stability of the composites.

\subsection{Differential Scanning Calorimetry (DSC)}

The melting and crystallization characteristics of the composites were evaluated using Perkin-Elmer DSC-7 Analyzer. The samples were heated from $30{ }^{\circ} \mathrm{C}$ to $200{ }^{\circ} \mathrm{C}$ at a heating rate of $10^{\circ} \mathrm{C} / \mathrm{min}$ in nitrogen atmosphere. The crystallinity of composite $\left(X_{C O M}\right)$ and crystallinity in rHDPE fraction $\left(X_{\text {RHDPE }}\right)$ before and after surface treatment were determined by using the Equations 1 and 2:

$$
\begin{aligned}
& \mathrm{X}_{\mathrm{com}}=\frac{\Delta \mathrm{H}_{\mathrm{f}}}{\Delta \mathrm{H}_{\mathrm{f}}^{0}} \times 100 \\
& \mathrm{X}_{\mathrm{rHDPE}}=\frac{\mathrm{X}_{\mathrm{c}}}{\mathrm{W}_{\mathrm{f}(\mathrm{rHDPE})}} \times 100
\end{aligned}
$$

where $\Delta H_{\mathrm{f}}$ is the heat of fusion of sample analyzed, $\Delta \mathrm{H}^{0}{ }_{F}$ $(\mathrm{PE})=293 \mathrm{~J} / \mathrm{g}^{[15]}$ is used for $100 \%$ crystalline HDPE homopolymer, and $W_{F(R H D P E)}$ is the weight fraction of rHDPE in the composite.

\section{Results and Discussions}

\subsection{FTIR}

FTIR spectra of KP and KP-APS are displayed in Figure 1A. The chemical modification of KP led to changes in a few peaks due to molecular interactions. For example, a peak at $1726 \mathrm{~cm}^{-1}$ was observed for the KP due to the unconjugated $\mathrm{C}=\mathrm{O}$ groups in hemicellulose. This peak fully disappeared after pretreatment with $\mathrm{NaOH}$. In addition, for the KP-APS, bands were observed at $1267 \mathrm{~cm}^{-1}$ and $710 \mathrm{~cm}^{-1}$ which correspond to $\mathrm{Si}-\mathrm{C}$ stretching and $\mathrm{Si}-\mathrm{O}-\mathrm{Si}$ stretching, respectively ${ }^{[16]}$. Another peak at $465 \mathrm{~cm}^{-1}$ is associated with Si-O-C asymmetric bending. These bands are simply due to the silanization reactions between APS and KP. The changes in these bands can also due to plausible interactions as illustrated in Figure 1B. The presence of $\mathrm{Si}-\mathrm{O}-\mathrm{Si}$ might also be detected as a shoulder in the peak located at $1060 \mathrm{~cm}^{-1[15]}$.

Figure 2 shows FTIR spectra of KP and KP-APSDCP. It can be seen that the introduction of APS led to the appearance of two new peaks at $1726 \mathrm{~cm}^{-1}$ and $1267 \mathrm{~cm}^{-1}$, corresponding to the carbonyl group of ester or acids ${ }^{[17]}$ and Si-C stretching of APS, respectively. A slight increase in peaks in the $1000-1080 \mathrm{~cm}^{-1}$ region should also be highlighted. The strengthening of these bands could be associated to the asymmetric stretching of Si-O-Si or Si$\mathrm{O}-\mathrm{C}$ bonds ${ }^{[16]}$. The $\mathrm{OH}$ stretching vibrations in the region $3100-3500 \mathrm{~cm}^{-1}$ were observed at a lower intensity for the treated composite.

This is evidence of the interactions between the hydroxyl groups in KP and the functional groups in APS. The double band at $1726 \mathrm{~cm}^{-1}$ might be related to the $\mathrm{C}=\mathrm{O}$ vibrations of amide since carboxyl groups formed during the processing of rHDPE/NR, which could react with the amino functionality of APS ${ }^{[18]}$. After addition of DCP and APS, the absorption peak of the $\mathrm{C}=\mathrm{C}$ group of NR $\left(1662 \mathrm{~cm}^{-1}\right)$ was significantly reduced, while the vinyl group of rHDPE did not appear in either untreated or treated samples. This indicates that the NR was more prone to crosslinking/grafting reactions than $\mathrm{rHDPE}$ since $\mathrm{NR}$ has a large number of $\mathrm{C}=\mathrm{C}$ groups. The above results confirm the chemical reactions between APS and KP and the existence of a crosslinked network, with possible bonds between the filler and the polymer matrix through grafting and crosslinking.

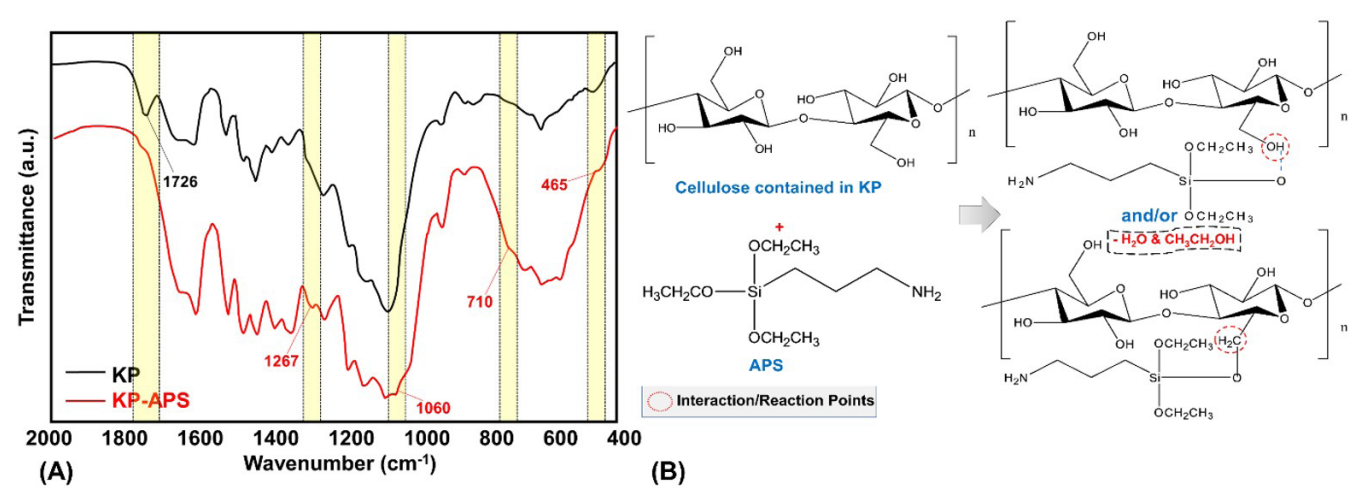

Figure 1. FTIR spectra of KP and KP-APS (A) and Plausible interaction between cellulose in KP and APS coupling agent (B). 


\subsection{Mixing torque}

The mixing torque of KP, KP-APS and KP-APS-DCP is shown in Figure 3A. All the curves have three distinct peaks corresponding to the materials input at certain stage. Basically, the torque decreased over time and reached a stable torque at the end of mixing cycle. In the case of KPAPS and KP-APS-DCP, a decrease in torque was observed before 6 min of mixing due to the lubricant action of the APS added. The decreasing slope for KP-APS-DCP sample was smaller than that of the others. This might be related to the crosslinking reactions taking place in the matrices and the stronger polymer-filler interactions in the presence

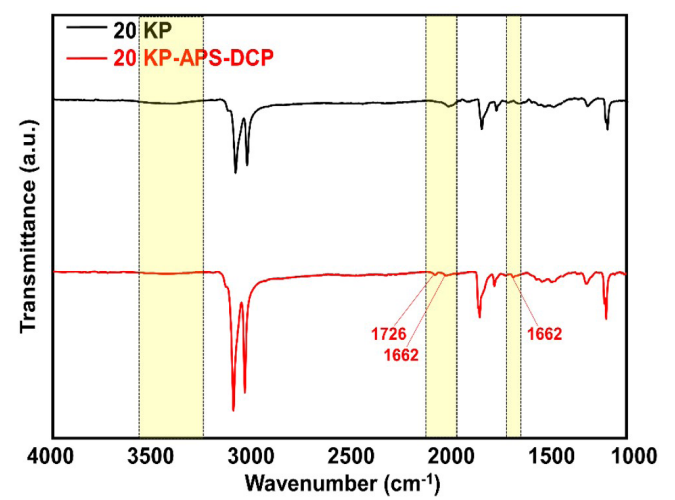

Figure 2. FTIR spectra of KP and KP-APS-DCP.
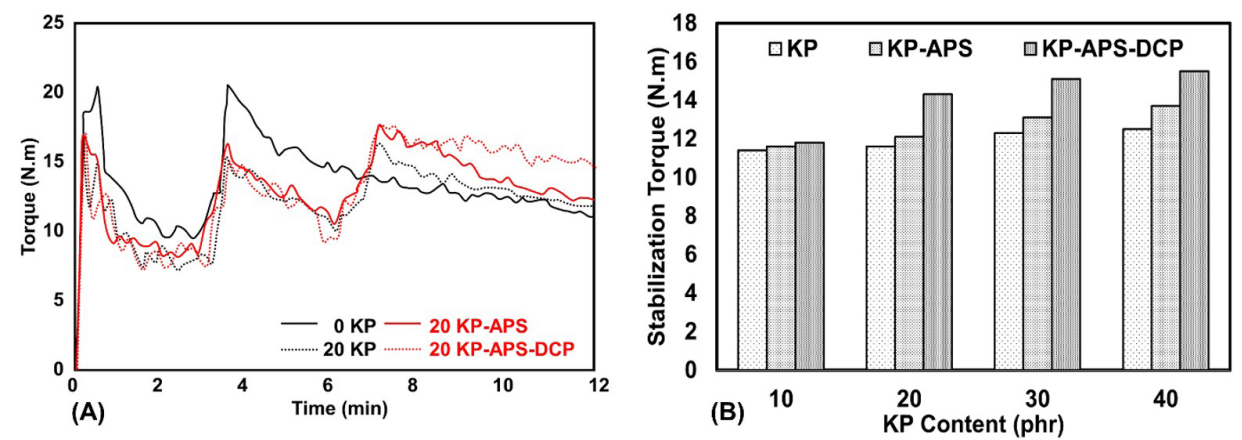

Figure 3. Time profiles of mixing torque (A) and stabilization torque (B) of KP, KP-APS and KP-APS-DCP.

Table 2. Tensile strength, elongation at break and Young's modulus of KP, KP-APS and KP-APS-DCP.

\begin{tabular}{|c|c|c|c|}
\hline Sample & Tensile strength (Mpa) & Elongation at break (\%) & Young's modulus (GPa) \\
\hline $10 \mathrm{KP}$ & $12.11 \pm 0.21$ & $115.51 \pm 13.1$ & $0.57 \pm 0.025$ \\
\hline 10KP-APS & $12.75 \pm 0.23$ & $62.50 \pm 10.0$ & $0.63 \pm 0.012$ \\
\hline 10KP-APS-DCP & $14.80 \pm 0.50$ & $360.15 \pm 27.2$ & $0.68 \pm 0.013$ \\
\hline $20 \mathrm{KP}$ & $11.92 \pm 0.41$ & $20.12 \pm 10.0$ & $0.62 \pm 0.022$ \\
\hline 20KP-APS & $12.32 \pm 0.25$ & $21.22 \pm 8.2$ & $0.63 \pm 0.013$ \\
\hline 20KP-APS-DCP & $14.05 \pm 0.73$ & $58.17 \pm 10.3$ & $0.74 \pm 0.012$ \\
\hline $30 \mathrm{KP}$ & $11.60 \pm 0.15$ & $12.50 \pm 5.0$ & $0.66 \pm 0.005$ \\
\hline 30KP-APS & $12.11 \pm 0.31$ & $9.21 \pm 3.1$ & $0.78 \pm 0.021$ \\
\hline 30KP-APS-DCP & $13.20 \pm 0.41$ & $26.09 \pm 4.9$ & $0.81 \pm 0.013$ \\
\hline $40 \mathrm{KP}$ & $10.92 \pm 0.62$ & $12.05 \pm 4.7$ & $0.71 \pm 0.007$ \\
\hline 40KP-APS & $11.61 \pm 0.40$ & $10.12 \pm 2.1$ & $0.79 \pm 0.014$ \\
\hline 40KP-APS-DCP & $13.40 \pm 0.25$ & $25.06 \pm 2.3$ & $0.83 \pm 0.013$ \\
\hline
\end{tabular}

of APS and DCP. Figure 3B illustrates effects of treatment type on stable torque of KP filled rHDPE/NR composites.

It can be observed that the stable torques of KP-APS and KP-APS-DCP were higher than that with KP. The treatment of KP with silane may lead to an increase in melt viscosity of the composites due to stronger interactions between filler and polymer. Meanwhile, the addition of APS and DCP into the composites led to a greater increase in stable torque as a result of crosslinking.

\subsection{Tensile properties}

Figure 4 displays typical stress-strain curves of KP, KP-APS and KP-APS-DCP. Generally speaking, both KP-APS and KP-APS-DCP cases had increased tensile strength and tensile modulus, and the KP-APS-DCP cases had distinctly positive effect on tensile strength. This is particularly at a low KP content (10 phr), a highest tensile strength was observed for KP-APS-DCP. There are two main factors affecting such improvement; one being due to an improve in polymer-filler interaction promoted by silane coupling agent another was simply due to the role of DCP itself which helps to promote co-crosslinking between rHDPE and NR. This has brougth to an increase in ultimate tensile strength of the composite.

Tensile strength elongation at break and Young's modulus of the composites are listed in Table 2. A better tensile strength was found in the composites with APS pretreatment. This is simply because of an improved filler dispersion in the matrix and a better degree of adhesion at the interfaces ${ }^{[19,20]}$. Also, 


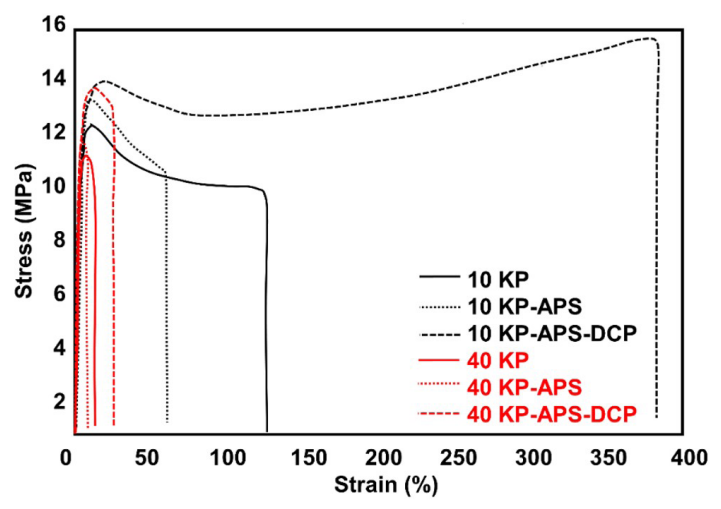

Figure 4. Stress-strain curves of KP, KP-APS and KP-APS-DCP.

thanks to a previous alkaline treatment that could remove impurities and wax from the fiber surfaces and create a rougher topography. Thus, physical interaction could be promoted and better adhesion was further enhanced by silane treatment ${ }^{[16]}$. The interaction between phases was expected to improve since the KP surfaces became less hydrophilic due to chemical bonding between APS and the OH groups ${ }^{[21]}$.

In contrast, when APS was used in combination with DCP (KP-APS-DCP), the tensile strength of this composite increased significantly with a maximum improvement of $23.7 \%$. This was possible through the following hypothetical mechanism of interaction between APS, KP and rHDPE/NR matrix. Firstly, the alkoxy groups in APS underwent hydrolysis. Moisture for the hydrolysis might come from the surface humidity of KP. Next, the attachment of silane to hydroxyl groups of fiber was accomplished through hydrogen bonds or through ether linkages (-O-) ${ }^{[22]}$. This accounted for the interface between KP and APS. The N-H group of APS might also react with $\mathrm{OH}$ groups of KP or other silane molecules. Thermal treatment is commonly applied to ensure that coupling agents adhere to the surface of cellulosic fibers ${ }^{[12,21]}$. In this case, it was strongly believed that the grafting reaction of APS on the surfaces of KP truly occurred during the mixing at $165^{\circ} \mathrm{C}$ (as confirmed by FTIR results). Regarding non-polar polymers like PE and NR, they have very little intrinsic reactivity since they do not contain any reactive groups. Thus, DCP was introduced to attack their molecular chains creating reactive sites for bonding. At an elevated temperature, DCP was firstly decomposed to produce an oxy radicals, these radicals had the potential to abstract hydrogen from rHDPE, NR or polymer parts of KP. Such polymer radicals are then free to interact each other through free-radical reaction ${ }^{[14]}$. Radical combinations might lead to the co-crosslinking of rHDPE and NR matrix as well as to grafting between KP and polymer matrix.

Table 2 also illustrates the effects of silane coupling agent on the elongation at break (Eb) of KP, KP-APS and KP-APS-DCP. Clearly the KP-APS treatment exhibited an adverse effect on Eb, while KP-APS-DCP showed the opposite trend. Lower Eb found in KP-APS was associated with the enhanced adhesion between filler and matrix. Better adhesion restricts the deformation capacity of a composite; thus catastrophic failure occurs after a comparatively small strain. In contrast, the elongation of KP-APS-DCP was greatly improved compared to the KP sample. It can be seen that the $\mathrm{Eb}$ at $10 \mathrm{phr}$ of KP was nearly $200 \%$ higher than that of the untreated composites. This is simply due to the crosslinking in the presence of DCP.

As for the tensile modulus or Young's modulus of the composites, there was an increase in tensile modulus with $\mathrm{KP}$ content due to this contributing a rigid phase. When considered at similar filler loadings, the moduli were higher for KP-APS-DCP than those for KP-APS and KP. This is quite surprising, since a reduction in tensile modulus is generally observed in both crosslinked PE and crosslinked PE composites filled with natural fiber as a result of decreased crystallinity of the matrix ${ }^{[23]}$. This indicates that the crosslinking degree of rHDPE was relatively low. The improved modulus could be related to better adhesion between the fiber and polymer matrix raised by silane coupling interaction. Better adhesion led to more restricted deformation capacity of the matrix in the elastic zone, and increased the modulus. It needs to be noted that the NR phase was also crosslinked, increasing stiffness of the composites. Elongation, tensile strength, and modulus followed similar trends, suggesting that the toughness of the resultant composites was improved by addition of APS.

According to Oksman and Clemons ${ }^{[24]}$, the toughness of a filled polymer composite can be responsible to several ways e.g., an increment in matrix toughness, an improve in interaction of filler and polymer matrix, or filler related properties such as filler content, filler particle size, and filler dispersion. In this work, crosslinking of rHDPE/NR in the presence of APS and DCP improved toughness of the polymer matrix. There was also indication of improved adhesion between KP filler and the rHDPE/NR matrix in the treated composites as discussed earlier. Therefore, a possible explanation for the improvement in all tensile properties of the KP-APS-DCP could be toughening of the matrix and better adhesion between filler and matrix.

\subsection{Morphological study}

The SEM micrographs of KP, KP-APS and KP-APS-DCP are shown in Figure 5. At a low filler content (10 phr), strong adhesion between the components was clearly detected. Indeed, the deformation of rHDPE matrix was prominent for composites treated with APS and DCP (KP-APS-DCP). A number of fibers attached on the matrix are visible, and less fiber pull-out is observed on the fractured surface. This indicates that the level of adhesion between filler and matrix was greatly improved. This behavior is related to the crosslinking in rHDPE and NR phases. This could be an explanation for the improved tensile strength and elongation at break of KP-APS-DCP at a low filler loading.

At a higher filler content (40 phr), the fractured surface showed less plastic flow or deformation of matrix compared to the composites with 10 phr of KP. However, the polymer-filler interactions of KP-APS-DCP were stronger than in the untreated composites (KP). The failure surface seemed to be uniform and both matrix and fiber appeared to fail simultaneously. Some fibers were firmly imbedded and coated in the matrix which indicates good wetting by the polymer. In addition, breakage of the fibers was also visible. This was further evidence supporting the concept 


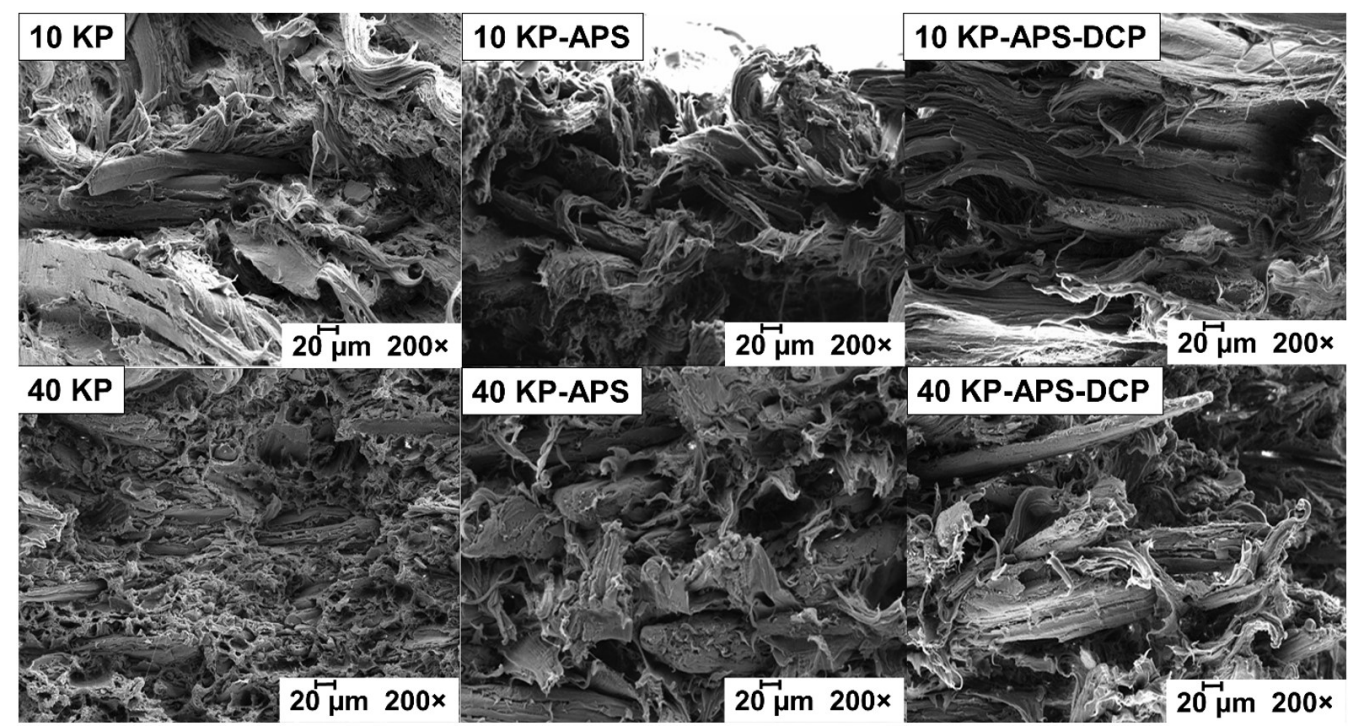

Figure 5. SEM micrographs of KP, KP-APS and KP-APS-DCP (200× magnification).

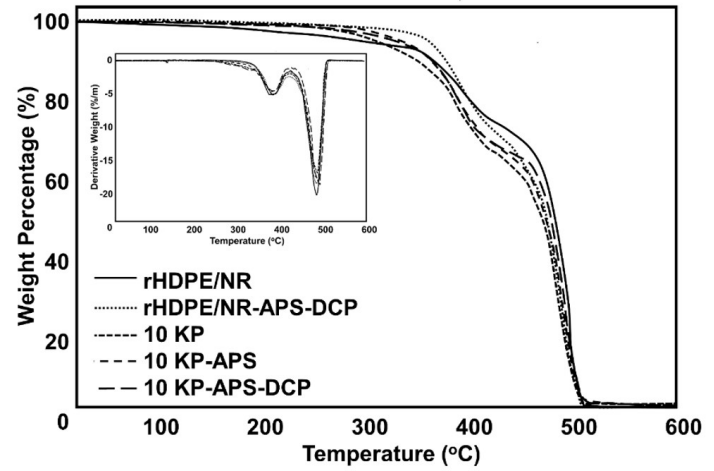

Figure 6. Typical TG and DTG curves of KP, KP-APS and KPAPS-DCP.

that APS and DCP improved interfacial adhesion between $\mathrm{KP}$ and polymer matrix.

\subsection{Thermogravimetric analysis (TGA)}

Figure 6 shows the TG profiles of KP, KP-APS and KP-APS-DCP. Summary of key temperatures read from the TGA and DTG curves including temperatures at 5\% $\left(\mathrm{T}_{5 \%}\right), 50 \%\left(\mathrm{~T}_{50 \%}\right)$ and maximum weight loss $\left(\mathrm{T}_{\mathrm{d}}\right)$ and weight residue $(W)$ is presented in Table 3 . Generally, the silane treatments improved thermal stability of the composites to some extent, particularly at a low filler content. This is clearly seen from the shifts in degradation temperature. Tserki et al. ${ }^{[25]}$, suggested that lignin and hemicelluloses exhibit poor thermal stability, while reversely effect was found for the fiber with a higher cellulose content. For the treatment of KP by silane, KP was firsly washed with $\mathrm{NaOH}$, this process has reduced the hemicelluloses and lignin to a considerable extent ${ }^{[14]}$, thus improving the thermal stability at this temperature range (disappearance of hemicellulose peak from the DTG curve). However, lignin seems to be more stable than cellulose and hemicellulose at high

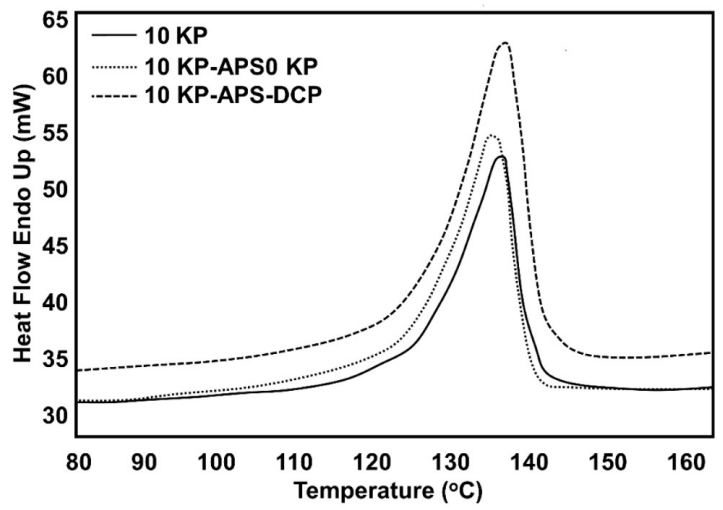

Figure 7. DSC thermograms of KP, KP-APS and KP-APS-DCP.

temperatures, hence the lower lignin content resulted in poorer thermal resistance at high temperatures. Alkaline pretreatment decreases the char yield since it removed a portion of the cell structure (hemicellulose or lignin) and eliminated some inorganic matter ${ }^{[26]}$. The KP-APS-DCP slightly modified the thermal stability of the composites. It appeared to be more thermally stable with $\mathrm{T}_{\mathrm{d}}$ temperature shifting from $487.3{ }^{\circ} \mathrm{C}$ to $491{ }^{\circ} \mathrm{C}$. This could be due to enhanced thermal degradation of $\mathrm{PE}$ and NR chains in the presence of $\mathrm{DCP}^{[27]}$. APS and DCP may induce grafting between the matrix and the filler, which improved thermal stability of the composite.

\subsection{Differential scanning calorimetry (DSC)}

DSC curves of KP, KP-APS and KP-APS-DCP are shown in Figure 7 and the thermal behavior of these composites is summarized in Table 4. The melting temperature of rHDPE in the modified samples was slightly lower than in the unmodified samples due to crosslinking of the matrix as well as grafting of PE chains to the fiber ${ }^{[22]}$. However, the temperature decrease was marginal. $\mathrm{T}_{\mathrm{m}}$ values of treated 
Table 3. TGA data of KP, KP-APS and KP-APS-DCP.

\begin{tabular}{|c|c|c|c|c|}
\hline Sample & $\mathrm{T}_{5 \%}\left({ }^{\circ} \mathrm{C}\right)$ & $\mathrm{T}_{50 \%}\left({ }^{\circ} \mathrm{C}\right)$ & $T_{d}\left({ }^{\circ} \mathrm{C}\right)$ & $W(\mathbf{\%})$ \\
\hline $10 \mathrm{KP}$ & 304.7 & 464.3 & 487.3 & 0.17 \\
\hline 10KP-APS & 331.0 & 470.0 & 488.6 & 0.98 \\
\hline 10KP-APS-DCP & 325.3 & 475.2 & 491.0 & 1.46 \\
\hline $40 \mathrm{KP}$ & 277.4 & 463.0 & 488.0 & 7.3 \\
\hline 40KP-APS & 289.1 & 461.6 & 488.2 & 5.92 \\
\hline 40KP-APS-DCP & 282.4 & 465.5 & 490.5 & 6.44 \\
\hline
\end{tabular}

Table 4. DSC parameters of KP, KP-APS and KP-APS-DCP.

\begin{tabular}{ccccc}
\hline Sample & $\mathbf{T}_{\mathbf{m}}\left({ }^{\circ} \mathbf{C}\right)$ & $\Delta H_{F / C O M}(\mathbf{J} / \mathbf{g})$ & $X_{C O M}(\mathbf{\%}$ crystalline $)$ & $X_{R H D P E}(\%)$ \\
\hline 10KP & 132.95 & 93.35 & 31.86 & 50.07 \\
10KP-APS & 131.89 & 99.65 & 34.0 & 53.43 \\
10KP (APS-DCP) & 131.51 & 98.51 & 33.62 & 52.83 \\
40KP & 132.58 & 75.49 & 25.76 & 51.52 \\
40 KP-APS & 132.46 & 84.28 & 28.76 & 57.52 \\
40KP (APS-DCP) & 132.29 & 85.5 & 29.18 & 58.36 \\
\hline
\end{tabular}

composites increased with the amount of filler, while untreated composites showed the opposite trend. In the case of KP-APS, the crystallinity increased significantly, which could be attributed to the good compatibility and improved interfacial adhesion between filler and matrix caused by fiber surface modification ${ }^{[28]}$.

It is also noted that the removal of hemicelluloses contributed to higher crystallinity of the fibers, and in the composites. This result is in agreement with the improved tensile strength and modulus, as discussed earlier. Similar results were also obtained for KP-APS-DCP, and DCP probably initiated crosslinking in NR or in the amorphous phase of PE, hence the extent of crystallization did not change in this phase. In addition to this, this composite also showed lower melting temperatures compared to the $\mathrm{KP}$, while the degree of crystallinity rose significantly. This indicates that DCP possibly initiated crosslinking in the NR phase or grafting of the polymer chains onto the kenaf fiber ${ }^{[29]}$. This observation is in accordance with the increased tensile modulus of KP-APS-DCP.

\section{Conclusion}

Surface modification of the KP with silane coupling agent (KP-APS) showed a better effect on tensile strength but the increment was not significant. It also improved the tensile modulus and reduced the elongation at break of the composites. The interactions between matrix and filler were expected to improve since the KP surfaces became less hydrophilic due to chemical bonding of silane to the hydroxyl groups on the surfaces. When APS was used in combination with DCP, all the tensile properties were significantly improved. This was attributed to the toughening of the matrix and better adhesion between filler and matrix induced by crosslinking/grafting reactions. The silane treatment also enhanced the thermal stability of the composites to some extent, particularly at a low filler content. DSC results revealed an increase in crystallinity of the treated biocomposites in both cases. The use of APS in combination with DCP to blend rHDPE and NR provided good physical and thermal stability. Hence, this formulation was clearly successful, and is highly recommended when the strength and thermal stability are of primary concern. This system can also be considered when there the blends are exposed to elevated temperatures during production or use

\section{References}

1. Favaro, S., Ganzerli, T., de Carvalho Neto, A., Da Silva, O., \& Radovanovic, E. (2010). Chemical, morphological and mechanical analysis of sisal fiber-reinforced recycled highdensity polyethylene composites. Express Polymer Letters, 4(8), 465-473. http://dx.doi.org/10.3144/expresspolymlett.2010.59.

2. Yam, K. L., Gogoi, B. K., Lai, C. C., \& Selke, S. E. (1990). Composites from compounding wood fibers with recycled high density polyethylene. Polymer Engineering and Science, 30(11), 693-699. http://dx.doi.org/10.1002/pen.760301109.

3. Burgoa, A., Hernandez, R., \& Vilas, J. L. (2020). New ways to improve the damping properties in high-performance thermoplastic vulcanizates. Polymer International, 69(5), 467-475. http://dx.doi.org/10.1002/pi.5977.

4. Huang, J., Fan, J., Cao, L., Xu, C., \& Chen, Y. (2020). A novel strategy to construct co-continuous PLA/NBR thermoplastic vulcanizates: metal-ligand coordination-induced dynamic vulcanization, balanced stiffness-toughness and shape memory effect. Chemical Engineering Journal, 385, 123828. http:// dx.doi.org/10.1016/j.cej.2019.123828.

5. Zheng, M., Zhang, S., Chen, Y., Wu, Q., Li, Q., \& Wang, S. (2020). Structure evolution of bio-based PLA/ENR thermoplastic vulcanizates during dynamic vulcanization processing. Polymer Testing, 82, 106324. http://dx.doi.org/10.1016/j. polymertesting.2020.106324.

6. Abdel-Hamid, S. M. S., Al-Qabandi, O. A., Elminshawy, N. A. S., Bassyouni, M., Zoromba, M. S., Abdel-Aziz, M. H., \& Mira, H. (2019). Fabrication and characterization of microcellular polyurethane sisal biocomposites. Molecules, 24(24), 4585. http://dx.doi.org/10.3390/molecules24244585. PMid:31847377.

7. Verheyen, S., Blaton, N., Kinget, R., \& Kim, H.-S. (2004). Thermogravimetric analysis of rice husk flour filled thermoplastic polymer composites. Journal of Thermal Analysis and Calorimetry, 76(2), 395-404. http://dx.doi. org/10.1023/B:JTAN.0000028020.02657.9b. 
8. Ismail, M. R., Yassen, A. A. M., \& Afify, M. S. (2011). Mechanical properties of rice straw fiber-reinforced polymer composites. Fibers and Polymers, 12(5), 648-656. http://dx.doi. org/10.1007/s12221-011-0648-5.

9. Schneider, J. P., Myers, G. E., Clemons, C. M., \& English, B. W. (1995). Biofibers as reinforcing fillers in thermoplastic composites. Journal of Vinyl and Additive Technology, 1(2), 103-108. http://dx.doi.org/10.1002/vnl.730010212.n.

10. Webber, C. L., 3rd, Whitworth, J., \& Dole, J. (1999). Kenaf (Hibiscus cannabinus L.) core as a containerized growth medium component. Industrial Crops and Products, 10(2), 97-105. http://dx.doi.org/10.1016/S0926-6690(99)00014-X.

11. Raj, R. G., Kokta, B. V., Dembele, F., \& Sanschagrain, B. (1989). Compounding of cellulose fibers with polypropylene: effect of fiber treatment on dispersion in the polymer matirx. Journal of Applied Polymer Science, 38(11), 1987-1996. http:// dx.doi.org/10.1002/app.1989.070381103.

12. Abdelmouleh, M., Boufi, S., Belgacem, M. N., \& Dufresne, A. (2007). Short naturalfibre reinforced polyethylene and natural rubber composites: effect of silane coupling agents and fibres loading. Composites Science and Technology, 67(7-8), 16271639. http://dx.doi.org/10.1016/j.compscitech.2006.07.003.

13. Kim, T.-W., Lee, S.-Y., Chun, S.-J., Doh, G.-H., \& Paik, K.-H. (2011). Effect of silane coupling on the fundamental properties of wood flour reinforced polypropylene composites. Journal of Composite Materials, 45(15), 1595-1605. http://dx.doi. org/10.1177/0021998310385589.

14. Tanrattanakul, V., \& Udomkichdecha, W. (2001). Development of novel elastomeric blends containing natural rubber and ultra-low-density polyethylene. Journal of Applied Polymer Science, 82(3), 650-660. http://dx.doi.org/10.1002/app.1893.

15. Alix, S., Philippe, E., Bessadok, A., Lebrun, L., Morvan, C., \& Marais, S. (2009). Effect of chemical treatments on water sorption and mechanical properties of flax fibres. Bioresource Technology, 100(20), 4742-4749. http://dx.doi.org/10.1016/j. biortech.2009.04.067. PMid:19477120.

16. Pereira, P. H. F., Rosa, M. F., Cioffi, M. O. H., Benini, K. C. C. C., Milanese, A. C., Voorwald, H. J. C., \& Mulinari, D. R. (2015). Vegetal fibers in polymeric composites: a review. Polímeros: Ciência e Tecnologia, 25(1), 9-22. http://dx.doi. org/10.1590/0104-1428.1722.

17. Pretsch, E., Bühlmann, P., \& Badertscher, M. (2009). Structure determination of organic compounds: tables of spectral data. Germany: Springer-Verlag. http://dx.doi.org/10.1007/978-3540-93810-1.

18. Demjén, Z., Pukánszky, B., \& Nagy, J., Jr. (1999). Possible coupling reactions of functional silanes and polypropylene. Polymer, 40(7), 1763-1773. http://dx.doi.org/10.1016/S00323861(98)00396-6.

19. Natarajan, S., Rathanasamy, R., Palaniappan, S. K., Velayudham, S., Subburamamurthy, H. B., \& Pal, K. (2020). Comparison of MA-g-PP effectiveness through mechanical performance of functionalised graphene reinforced polypropylene.
Polimeros: Ciência e Tecnologia, 30(3), e2020035. http:// dx.doi.org/10.1590/0104-1428.05620.

20. Cui, Y., Lee, S., Noruziaan, B., Cheung, M., \& Tao, J. (2008). Fabrication and interfacial modification of wood/recycled plastic composite materials. Composites. Part A, Applied Science and Manufacturing, 39(4), 655-661. http://dx.doi. org/10.1016/j.compositesa.2007.10.017.

21. Castellano, M., Gandini, A., Fabbri, P., \& Belgacem, M. N. (2004). Modification of cellulose fibres with organosilanes: under what conditions does coupling occur? Journal of Colloid and Interface Science, 273(2), 505-511. http://dx.doi. org/10.1016/j.jcis.2003.09.044. PMid:15082387.

22. Xie, Y., Hill, C.A. S., Xiao, Z., Militz, H., \& Mai, C. (2010). Silane coupling agents used for natural fiber/polymer composites: a review. Composites. Part A, Applied Science and Manufacturing, 41(7), 806-819. http://dx.doi.org/10.1016/j.compositesa.2010.03.005.

23. Grubbström, G., Holmgren, A., \& Oksman, K. (2010). Silane-crosslinking of recycled low-density polyethylene/ wood composites. Composites. Part A, Applied Science and Manufacturing, 41(5), 678-683. http://dx.doi.org/10.1016/j. compositesa.2010.01.018.

24. Oksman, K., \& Clemons, C. (1998). Mechanical properties and morphology of impact modified polypropylene-wood flour composites. Journal of Applied Polymer Science, 67(9), 1503-1513. http://dx.doi.org/10.1002/(SICI)10974628(19980228)67:9<1503::AID-APP1>3.0.CO;2-H.

25. Tserki, V., Zafeiropoulos, N. E., Simon, F., \& Panayiotou, C. (2005). A study of the effect of acetylation and propionylation surface treatments on natural fibres. Composites. Part A, Applied Science and Manufacturing, 36(8), 1110-1118. http://dx.doi. org/10.1016/j.compositesa.2005.01.004.

26. Shebani, A. N., van Reenen, A. J., \& Meincken, M. (2008). The effect of wood extractives on the thermal stability of different wood species. Thermochimica Acta, 471(1-2), 43-50. http:// dx.doi.org/10.1016/j.tca.2008.02.020.

27. Marcovich, N. E., \& Villar, M. A. (2003). Thermal and mechanical characterization of linear low-density polyethylene/ wood flour composites. Journal of Applied Polymer Science, 90(10), 2775-2784. http://dx.doi.org/10.1002/app.12934.

28. Bouza, R., Lasagabaster, A., Abad, M. J., \& Barral, L. (2008). Effects of vinyltrimethoxy silane on thermal properties and dynamic mechanical properties of polypropylene-wood flour composites. Journal of Applied Polymer Science, 109(2), 1197-1204. http://dx.doi.org/10.1002/app.28159.

29. Khonakdar, H. A., Morshedian, J., Wagenknecht, U., \& Jafari, S. H. (2003). An investigation of chemical crosslinking effect on properties of high-density polyethylene. Polymer, 44(15), 4301-4309. http://dx.doi.org/10.1016/S0032-3861(03)00363-X.

Received: May 06, 2021

Revised: Aug. 21, 2021

Accepted: Aug. 23, 2021 